\title{
Wide Bandgap Random Terpolymers for High Efficiency Halogen-Free Solvent Processed Polymer Solar Cells
}

\author{
GUO Xia ${ }^{1}$, FAN Qunping ${ }^{1}$, CUI Chaohua ${ }^{1}$, ZHANG Zhiguo ${ }^{2}$, ZHANG Maojie ${ }^{1, *}$ \\ ${ }^{1}$ Laboratory of Advanced Optoelectronic Materials, College of Chemistry, Chemical Engineering and Materials Science, \\ Soochow University, Suzhou 215123, Jiangsu Province, P. R. China. \\ ${ }^{2}$ CAS Key Laboratory of Organic Solids, Institute of Chemistry, Chinese Academy of Sciences, Beijing 100190, P. R. China.
}

\begin{abstract}
Over the past two decades, bulk heterojunction polymer solar cells (PSCs) have attracted significant attention owing to their potential applications in the mass fabrication of flexible device panels by roll-to-roll printing. To improve the photovoltaic performance of PSCs, much effort has been devoted to the optimization of properties of donor-acceptor (D-A) type polymer donor materials. Until now, the development of high-performance donor polymers is mainly dependent on the design and synthesis of binary polymers with a regular D/A alternating skeleton. Compared to binary polymers, random terpolymers with three different donor or acceptor monomer units possess synergetic effects of their inherent properties, such as optical absorption ability, energy levels, crystallinity, charge mobility, and morphological compatibility with the

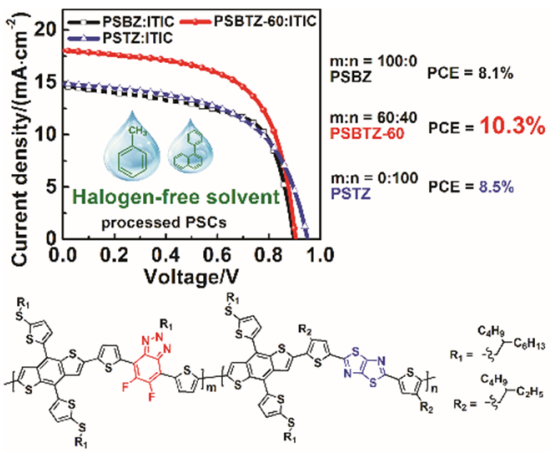
$n$-OS acceptors with suitable adjustment of the molar ratio of the three monomers. However, the irregularity in the polymer backbone of the random terpolymers may have an adverse effect on molecular packing, crystallinity, and charge mobility. Therefore, design and synthesis of high-performance terpolymers for PSCs is a challenging task. In this study, a series of wide bandgap random terpolymers PSBTZ-80, PSBTZ-60, and PSBTZ-40 based on alkylthiothienyl substituted benzodithiophene as the donor unit and two weak electron-deficient acceptor units of 5,6-difluorobenzotriazole (FBTz) and thiazolothiazole (TTz) were designed and synthesized for PSC applications. The optical, electrochemical, molecular packing, and photovoltaic properties of the polymers were effectively modulated by varying the FBTz:TTz molar ratio. Therefore, the PSC based on PSBTZ-60 as the donor material and narrow bandgap small molecule 3,9-bis(2-methylene(3-(1,1-dicyanomethylene)-indanone))-5,5,11,11-tetrakis(4-hexyl-phenyl)-dithieno[2,3-d:2',3'- $\left.d^{\prime \prime}\right]$-s-indaceno[1,2-b:5,6- $\left.b^{\prime}\right]$ di thiophene) (ITIC) as the acceptor, processed using halogen-free solvents, exhibited high power conversion efficiency (PCE) of $10.3 \%$ with high open-circuit voltage $\left(V_{\mathrm{oc}}\right)$ of $0.91 \mathrm{~V}$, improved short-circuit current density $\left(\mathrm{J}_{\mathrm{sc}}\right)$ of $18.0 \mathrm{~mA} \cdot \mathrm{cm}^{-2}$, and fill factor (FF) of $62.7 \%$, which are superior to those of PSCs based on binary polymers PSBZ (a PCE of $8.1 \%, V_{\text {oc }}$ of $0.89 \mathrm{~V}, \mathrm{~J}_{\mathrm{sc}}$ of $14.7 \mathrm{~mA} \cdot \mathrm{cm}^{-2}$, and FF of $61.5 \%$ ) and PSTZ (a PCE of $8.5 \%, V_{\mathrm{oc}}$ of $0.96 \mathrm{~V}, \mathrm{~J}_{\mathrm{sc}}$ of $14.9 \mathrm{~mA} \cdot \mathrm{cm}^{-2}$, and $\mathrm{FF}$ of $59.1 \%)$. These results indicate that random terpolymerization is a simple and practical strategy for the development of high-performance polymer photovoltaic materials.
\end{abstract}

Key Words: Terpolymer; Polymer solar cells; Halogen-free solvent; Power conversion efficiency

Received: March 29, 2018; Revised: April 2, 2018; Accepted: April 2, 2018; Published online: April 9, 2018.

${ }^{*}$ Corresponding author. Email: mjzhang@suda.edu.cn; Tel.: +86-0512-65883576.

The project was supported by the National Natural Science Foundation of China (51573120, 51503135, 51773142, 91633301), and Jiangsu Provincial Natural Science Foundation, China (BK20150332).

国家自然科学基金(51573120,51503135, 51773142,91633301)和江苏省自然科学基金(BK20150332)资助项目

(C) Editorial office of Acta Physico-Chimica Sinica 


\title{
基于无规三元共聚物的非卤溶液加工型高效聚合物太阳能电池
}

\author{
国霞 ${ }^{1}$, 凡群平 ${ }^{1}$, 崔超华 ${ }^{1}$, 张志国 2 , 张茂杰 ${ }^{1,}{ }^{*}$ \\ 1 苏州大学材料与化学化工学部, 先进光电材料实验室, 江苏苏州 215123 \\ 2 中国科学院化学研究所, 中国科学院有机固体重点实验室, 北京 100190
}

\begin{abstract}
摘要: 在本工作中, 我们以烷硫基噻吩基取代的苯并二噻吩(BDTT-S)为给体单元、5,6-二氟取代苯并三唑(FBTz)和噻唑 并噻唑 $(\mathrm{TTz})$ 为弱吸收电子受体单元, 设计合成了一系列宽带隙的无规三元共聚物给体材料。通过改变两个受体单元FBTz 和TTz在聚合物中的摩尔比, 有效调节了聚合物的光学、电化学、分子排列以及电荷传输性能。最终, 使用非卤溶剂为 加工溶剂, 以三元共聚物PSBTZ-60为给体、ITIC为非富勒烯受体的聚合物太阳能电池(PSCs)获得了 10.3\%的能量转换 效率 $(P C E)$, 其中开路电压为 $0.91 \mathrm{~V}$, 短路电流为 $18.0 \mathrm{~mA} \cdot \mathrm{cm}^{-2}$, 填充因子为 $62.7 \%$; 与之相比, 在相同的器件制备条 件下, 基于PSTZ:ITIC的PSCs仅获得 $8.5 \%$ 的PCE, 基于PSBZ:ITIC的PSCs也仅获得 $8.1 \%$ 的PCE。这些结果表明: 三元 无规共聚能够作为一种简单且实用的策略去设计、合成高性能聚合物光伏材料。
\end{abstract}

关键词: 三元共聚物; 聚合物太阳能电池; 非卤溶剂; 能量转化效率 中图分类号: 0646

\section{Introduction}

In the last four years, the polymer solar cells (PSCs) based on $n$-type organic semiconductor (n-OS) acceptor have emerged and made great progress ${ }^{1-6}$, and the corresponding power conversion efficiencies (PCEs) have exceeded $13 \%$ to date ${ }^{7-9}$. Recently, narrow bandgap (NBG) small molecule acceptors based on a fused-ring electron-donating core along with two strong electron-withdrawing end-groups have dominated high efficiency PSCs ${ }^{10-20}$, especially the most widely studied ITIC ${ }^{10}$. In comparison with the traditional fullerene derivatives (such as $\mathrm{PC}_{71} \mathrm{BM}$ and ICBA), the $n$-OS acceptor ITIC show wide absorption spectrum with small optical bandgap $\left(E_{\mathrm{g}}^{\mathrm{opt}}\right)$ of ca. $1.58 \mathrm{eV}$ and high absorption coefficient of $10^{5} \mathrm{~cm}^{-1}$ in the thin film processed with toluene, suitable molecular energy levels, and high electron mobility. So far, the PSCs based ITIC as acceptor have achieved the PCEs of more than $12 \%{ }^{11}$.

The well-matched pair of polymer donor and $n$-OS acceptor plays a key role in achieving efficient PSCs. By now, the development of high-performance donor polymers is mainly dependent on the design and synthesis of binary polymers with a regular D/A alternating skeleton ${ }^{21-32}$. However, only a few polymer donor materials have been successfully applied to the PSCs and achieved high PCE values. For example, Hou et al. ${ }^{21}$ reported a high performance wide bandgap (WBG) polymer PBDB-T with a skeleton of thienyl benzodithiophene (BDTT)alt-benzodithiophene-4,8-dione (BDD). In comparison with the PBDB-T:PC ${ }_{71} \mathrm{BM}$-based PSCs, the PSCs based on PBDB-T:ITIC showed a higher PCE of $11.21 \%$ due to the complementary absorption spectra and lower energy loss ( $E_{\text {loss, }}$ which is defined as $E_{\mathrm{g}}^{\mathrm{opt}}-e V_{\mathrm{oc}}$ ). Bin et al. also developed a series of high performance WBG polymers with a skeleton of BDTT-alt-benzotriazole (BTz) ${ }^{22-24}$, especially alkylthio and fluorine substituted 2D-conjugated polymer J61 ${ }^{22}$. Combined with ITIC acceptor, the PSCs achieved a high PCE of 9.53\% with a high short-circuit current density $\left(J_{\mathrm{sc}}\right)$ of $17.43 \mathrm{~mA} \cdot \mathrm{cm}^{-2}$ due to the high absorption coefficient and strong crystallinity of polymer J61. Recently, our group reported a high performance polymer donor PSBZ ${ }^{25}$ through the side-chain engineering on J61. Compared to J61, PSBZ showed stronger $\pi-\pi$ interaction and smaller stacking spacing leading to higher absorption coefficient and hole mobility. As a result, the halogenated solvent processed PSCs based on PSBZ:ITIC gained a PCE of up to $10.5 \%$ with a high $J_{\text {sc }}$ of $19.0 \mathrm{~mA} \cdot \mathrm{cm}^{-2}$. Very recently, our group designed a BDTT-alt-thiazolothiazole (TTz)-structured WBG polymer PSTZ ${ }^{29}$, and the PSTZ:ITIC-based PSCs still achieved a PCE of $8.13 \%$ when the open-circuit voltage $\left(V_{\text {oc }}\right)$ was up to $1.01 \mathrm{~V}$.

Recently, a random terpolymerization strategy, in which three different donor or acceptor monomers unite together to polymerize, has been applied to achieve synergetic effects of their inherent properties, such as optical absorption ability, energy levels, charge mobility and morphological compatibility with the fullerene derivative acceptors ${ }^{33-36}$. However, the irregularity in the polymer backbone of the random terpolymers may have an adverse effect on molecular packing, crystallinity, and charge mobility. Moreover, highly efficient PSCs based on terpolymer are rarely reported ${ }^{37}$. Therefore, it is a challenging work to design and synthesized a high performance terpolymer for PSCs.

\section{Results and discussion}

Synthetic routes of the binary polymers and random terpolymers were shown in Fig. 1. The monomers BDDT-S ${ }^{25}$, $\mathrm{FBTz}^{22}$ and $\mathrm{TTz}^{29}$ were synthesized in accordance with our previous methods. Polymers were obtained by Stille-coupling 


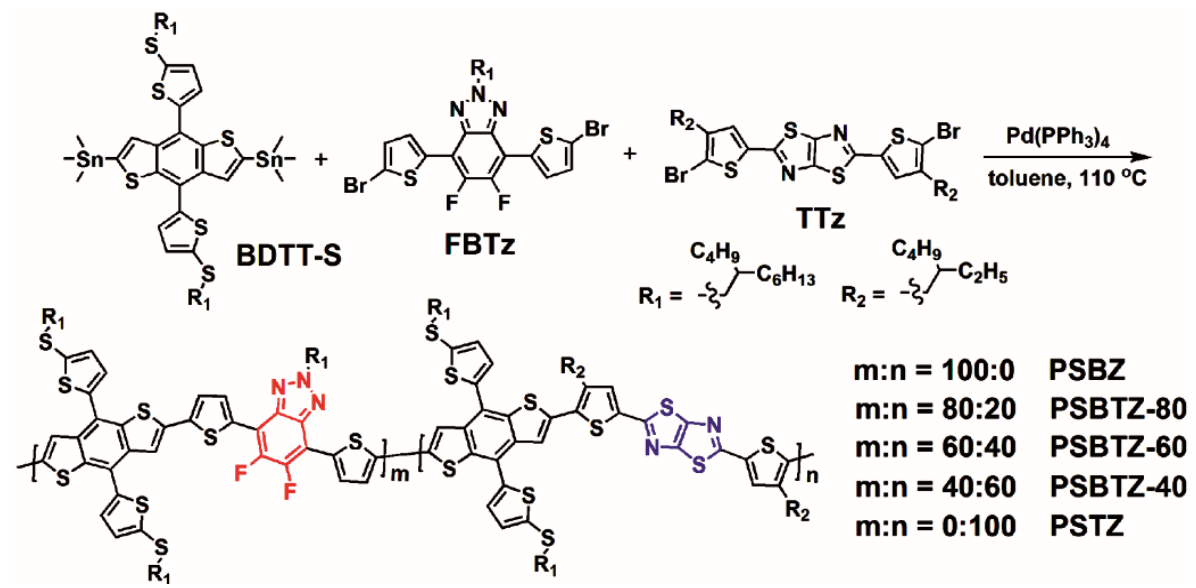

Fig. 1 Synthetic routes and molecular structures of the binary polymers PSBZ and PSTZ, and random terpolymers PSBTZ-80,

PSBTZ-60 and PSBTZ-40.
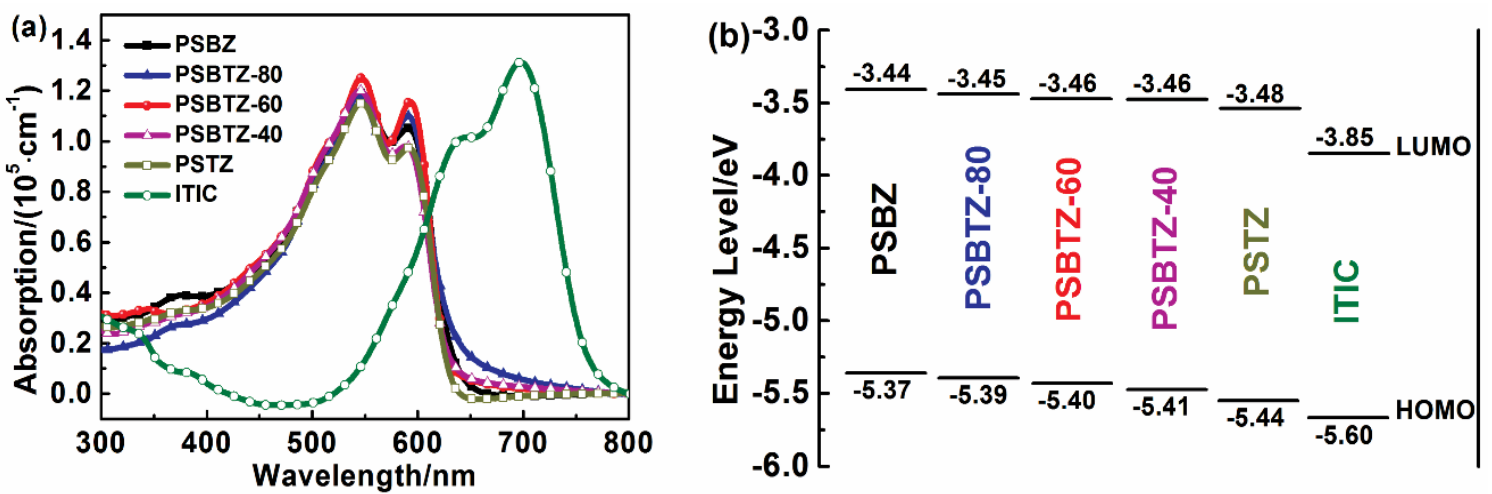

Fig. 2 (a) Absorption spectra and (b) molecular energy levels diagrams of the polymer donors and ITIC acceptor.

polymerization between BDDT-S, FBTz and TTz. Detailed synthesis procedures are described in Supporting Information (SI). The actual molecular composition of these polymers was determined by elemental analysis. The results showed that the BDDT-S/FBTz/TTz ratio in polymers were consistent with the molar feed ratio of BDDT-S/FBTz/TTz in polymerizations. The number/weight average molecular weights are 20.6/46.5, $21.8 / 47.3,21.3 / 48.9,22.2 / 46.8$, and $19.9 / 45.3 \mathrm{kDa}$ with the polydispersity index of $2.26,2.17,2.29,2.11$, and 2.28 for polymers PSBZ, PSBTZ-80, PSBTZ-60, PSBTZ-40, and PSTZ, as estimated by gel permeation chromatography using high temperature $\left(160^{\circ} \mathrm{C}\right)$ 1,2,4-trichlorobenzene as the eluent. All polymers display good solubility in many common organic solvents such as toluene, chloroform, and chlorobenzene.

Fig. 2a shows the UV-Vis absorption spectra of polymer donors and ITIC acceptor in thin film prepared by the toluene solutions. All five polymers show the similar absorption spectra with a maximum absorption $\left(\lambda_{\max }\right)$ peak at ca. 545 and an obvious absorption shoulder peak at ca. $594 \mathrm{~nm}$, especially PSBTZ-60. The PSBTZ-60 film has a maximum absorption coefficient of $1.25 \times 10^{5} \mathrm{~cm}^{-1}$, which is higher than those of binary polymers PSBZ $\left(1.19 \times 10^{5} \mathrm{~cm}^{-1}\right)$ and PSTZ $\left(1.15 \times 10^{5}\right.$ $\left.\mathrm{cm}^{-1}\right)$ as well as terpolymers PSBTZ-80 $\left(1.19 \times 10^{5} \mathrm{~cm}^{-1}\right)$ and PSBTZ-40 $\left(1.20 \times 10^{5} \mathrm{~cm}^{-1}\right)$. Moreover, polymer films have the similar absorption edges of ca. $637 \mathrm{~nm}$ and an $E_{\mathrm{g}}^{\mathrm{opt}}$ of ca.
$1.95 \mathrm{eV}$, which is absorption complementary to ITIC acceptor (an $E_{\mathrm{g}}^{\mathrm{opt}}$ of ca. $1.58 \mathrm{eV}$ ) in the Vis-NIR region.

The energy levels of the polymer donors and ITIC acceptor were summarized in Fig. 2b. With the increase in the proportion of TTz unit, the polymers show gradually lower energy levels. The highest occupied molecular orbital (HOMO) and the lowest unoccupied molecular orbital (LUMO) energy levels are $-5.37 /-3.44,-5.39 /-3.45,-5.40 /-3.46,-5.41 /-3.46$, and $-5.44 /-3.48 \mathrm{eV}$ for the PSBZ, PSBTZ-80, PSBTZ-60, PSBTZ-40, and PSTZ, respectively. The low HOMO level is beneficial for the related polymer donors to obtain higher $V_{\text {oc }}$ in PSCs ${ }^{38-40}$.

The PSCs with a device structure of ITO/ZnO/PFN/ polymers: ITIC/ $\mathrm{MoO}_{3} / \mathrm{Al}$ were fabricated to probe the photovoltaic properties of polymers, and the detailed preparation processes are recorded in SI. The current-voltage $(J-V)$ characteristics of the PSCs are shown in Fig. S1 (SI) and detailed photovoltaic parameters are summarized in Table S1-S3 (SI)). Firstly, we use halogen-free toluene as solvent and a $\mathrm{D} / \mathrm{A}$ weight ratio of $1 / 1$ to select the optimal polymer for the device optimization. Compared to the other PSCs based on polymers:ITIC, the PSBTZ-60:ITIC-based PSCs achieved a higher PCE of $9.1 \%$ due to the relatively higher $J_{\mathrm{sc}}$ of 16.5 $\mathrm{mA} \cdot \mathrm{cm}^{-2}$. Secondly, the D/A weight ratios of the PSBTZ-60:ITIC-based PSCs were optimized and found that the 

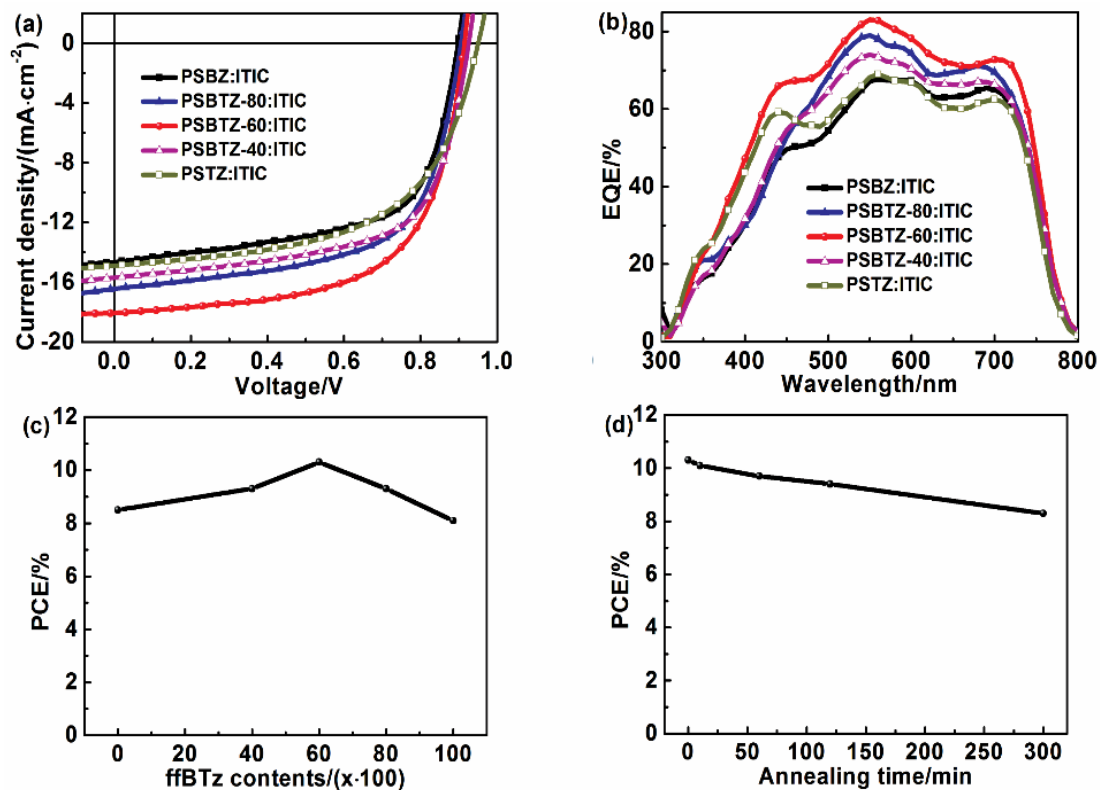

Fig. 3 (a) The $J-V$ curves and (b) EQE plots of the polymers:ITIC-based PSCs processed with $1 \%$ DPE. (c) The PCE versus FBTz contents in polymers. (d) The PCE versus annealing time of the PSBZT-60:ITIC-based PSCs under a temperature of $100{ }^{\circ} \mathrm{C}$.

optimum ratio was $1 / 1$ (see Fig. S1b and Table S2 in SI). Subsequently, the active layer morphology was optimized to improve the device performance by adding halogen-free diphenyl ether (DPE) as solvent additive. With the blend films processed with $1 \%$ DPE in volume, the PSCs showed an obviously increased $J_{\mathrm{sc}}$ from 16.5 to $18.0 \mathrm{~mA} \cdot \mathrm{cm}^{-2}$ and significantly improved FF from $58.5 \%$ to $62.7 \%$, while the $V_{\text {oc }}$ was slightly decreased to $0.91 \mathrm{~V}$. As a result, the champion PSC achieves a high PCE of $10.3 \%$ (see Fig. S1c and Table S3 in SI).

In order to facilitate comparison, the $J-V$ and $\mathrm{EQE}$ curves of PSCs processed with 1\% DPE was summarized in Fig. 3a and Fig. 3b, and the corresponding device performance date was summarized in Table 1. The active layer thicknesses of these devices are ca. $100 \mathrm{~nm}$. Compared with the other PSCs based on ITIC as acceptor and binary polymer as donor, the PSCs based on PSBTZ-60:ITIC showed obviously improved $J_{\text {sc }}$ from 14.7 and 14.9 to $18.0 \mathrm{~mA} \cdot \mathrm{cm}^{-2}$, slightly increased $\mathrm{FF}$ from $61.5 \%$ and $59.1 \%$ to $62.7 \%$, and moderate $V_{\text {oc }}$ of $0.91 \mathrm{~V}$. Moreover, the PSBTZ-60-based PSCs also displayed an obviously improved $J_{\mathrm{sc}}$ compared to the PSCs based on PSBTZ-80 or PSBTZ-40, which is consistent with PSBTZ-60 has a higher absorption coefficient. As shown in Fig. 3c, with the increase of FBTz acceptor content in the polymers, the PCE values of the related PSCs are first increased from $8.1 \%$ to $10.3 \%$, and then decreased to $8.5 \%$, while the highest PCE is gained for polymer PSBTZ-60 with an FBTz content of $60 \%$. Moreover, the optimal device possesses a low Eloss of ca. 0.57 $\mathrm{eV}$, which is lower the empirical threshold of $0.6 \mathrm{eV}$.

In addition to high efficiency, excellent thermal stability is also important for the practical applications of PSCs in future. Herein, we have tested the thermal stability of the PSC devices, as shown in Fig. S2 and Table S4 in SI. The devices annealed at a typical high temperature of $100{ }^{\circ} \mathrm{C}$ for $120 \mathrm{~min}$ in the $\mathrm{N}_{2}$-filled glovebox still remained a high PCE of $9.4 \%$ due to the almost unchanged $V_{\text {oc }}$, slightly improved FF, although $J_{\text {sc }}$ is decreased to some extent. As shown in Fig. 3d, with the high temperature annealing time extended to $300 \mathrm{~min}$, the PSCs still achieved a PCE of $8.3 \%$, which is ca. $81 \%$ of the original device efficiency. The above results indicate that the PSBTZ-60:ITIC-based PSCs possess high long-term thermal storage stability.

To confirm the high $J_{\mathrm{sc}}$ of the PSCs, the EQE tests were carried out (Fig. 3b). Compared to the devices based on binary polymers, the devices based on terpolymers show higher EQE response values, especially the PSBTZ-60:ITIC-based device. Moreover, the PSBTZ-60:ITIC-based device possesses a higher maximum EQE value of ca. $81 \%$ at $554 \mathrm{~nm}$ in comparison with the devices based on polymer donors PSBZ (ca. 68\% at 565 $\mathrm{nm}$ ), PSBTZ-80 (ca. $78 \%$ at $550 \mathrm{~nm}$ ), PSBTZ-40 (ca. $74 \%$ at $551 \mathrm{~nm}$ ), and PSTZ (ca. $69 \%$ at $560 \mathrm{~nm}$ ). The corresponding integral $J_{\text {sc }}$ values from EQE are 14.2, 15.8, 17.3, 15.2, and $14.5 \mathrm{~mA} \cdot \mathrm{cm}^{-2}$, which are well agree with the measured $J_{\mathrm{sc}}$ values.

The exciton dissociation and charge extraction processes are

Table 1 Photovoltaic performance date of the PSCs based on polymers:ITIC processed with $1 \%$ DPE.

\begin{tabular}{cccccc}
\hline Polymer & $V_{\mathrm{oc}} / \mathrm{V}$ & $J_{\mathrm{sc}}^{\mathrm{a}} /\left(\mathrm{mA} \cdot \mathrm{cm}^{-2}\right)$ & $\mathrm{FF} / \%$ & $\mathrm{PCE} / \%$ & Thickness $\mathrm{c} / \mathrm{nm}$ \\
\hline PSBZ & 0.89 & $14.7(14.2)$ & 61.5 & $8.1(7.9)$ & 100 \\
PSBTZ-80 & 0.90 & $16.5(15.8)$ & 62.4 & $9.3(9.1)$ & 103 \\
PSBTZ-60 & 0.91 & $18.0(17.3)$ & 62.7 & $10.3(10.0)$ & 102 \\
PSBTZ-40 & 0.93 & $15.7(15.2)$ & 63.2 & $9.3(9.0)$ & 105 \\
PSTZ & 0.96 & $14.9(14.5)$ & 59.1 & $8.5(8.3)$ & 97 \\
\hline
\end{tabular}

${ }^{\mathrm{a}}$ The integral $J_{\mathrm{sc}}$ in parentheses from the EQE curves. ${ }^{\mathrm{b}}$ The average PCEs in parentheses from 10 devices. ${ }^{\mathrm{c}}$ The average active layer thickness from 10 devices. 

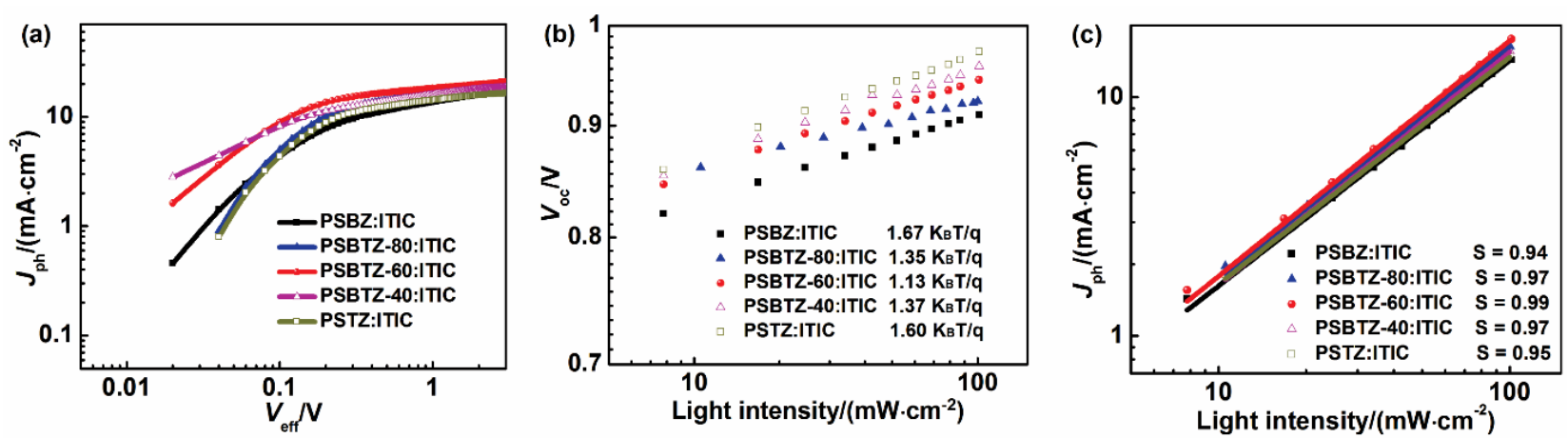

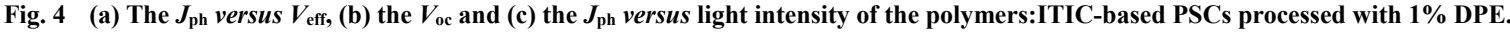

probed by measuring the plots of photocurrent $\left(J_{\mathrm{ph}}\right)$ versus effective voltage $\left(V_{\text {eff }}\right)$ of the devices (Fig. 4a) ${ }^{41-44}$. The parameter definitions and calculation methods are described in detail in SI. Under the maximum power output conditions, the exciton dissociation probabilities $P(E, T)$ were calculated to be $78.8 \%, 84.2 \%, 88.8 \%, 83.7 \%$, and $81.8 \%$ for the devices based on polymer donors PSBZ, PSBTZ-80, PSBTZ-60, PSBTZ-40, and PSTZ respectively, which implies that the PSC based on PSBTZ-60 possesses a more efficient exciton dissociation and charge extraction processes. To study the charge recombination mechanism in PSCs, the relationship of $V_{\text {oc }}$ with light intensity $(P)$ was probed (Fig. 4b) ${ }^{41,9}$. The slope of $V_{\text {oc }}$ versus $\ln P$ at $k \mathrm{~B} T / q$ suggests that the device only has bimolecular recombination, while the slope of $2 k \mathrm{~B} T / q$ means that the trap-assisted recombination dominates in the recombination mechanisms of device (where $T, k_{\mathrm{B}}$ and $q$ are the Kelvin temperature, Boltzmann constant and elementary charge, respectively). The device based on PSBTZ-60 (1.13k $\left.k_{\mathrm{B}} T / q\right)$ displays a smaller slope compared to the devices based on polymer donors PSBZ $\left(1.67 k_{\mathrm{B}} T / q\right)$, PSBTZ-80 (1.35k $\left.k_{\mathrm{B}} T / q\right)$, PSBTZ-40 (1.37k $\left.k_{\mathrm{B}} T / q\right)$, and PSTZ $\left(1.60 k_{\mathrm{B}} T / q\right)$, which implies that the PSBTZ-60:ITIC-based device has fewer trap-assisted recombination. Moreover, the dependence of $J_{\mathrm{ph}}$ under different $P$ was defined as $J_{\mathrm{ph}} \propto P^{S}$, and studied to further probe the charge recombination process in PSCs (Fig. 4c). $S$ values close to 1 indicate that the devices possess weak bimolecular recombination 41,27 . For the devices based on polymer donors PSBZ, PSBTZ-80, PSBTZ-60, PSBTZ-40, and PSTZ, the $S$ values of the fitted lines in logarithmic coordinates are 0.94 , $0.97,0.99,0.97$, and 0.95 respectively, which means that the PSBTZ-60-based device has less bimolecular recombination.

Photoluminescence (PL) quenching efficiencies of the polymers:ITIC blend films compared to their pure polymer or ITIC films were also measured to probe the exciton dissociation and charge transport processes (Fig. 5 and Fig. S3 in SI). At a excitation wavelength of $700 \mathrm{~nm}$ come from ITIC film, the PSBTZ-60:ITIC blend film shows a higher PL quenching efficiency of more than $95 \%$ in comparison with the other PSBZ:ITIC (86.3\%), PSBTZ-80:ITIC (89.1\%), PSBTZ-40:ITIC (89.7\%), and PSTZ:ITIC (84.7\%) blend films. Similar phenomena are also found at an excitation wavelength of $550 \mathrm{~nm}$ come from polymer donors (Fig. S3 in SI), implying that the devices based on PSBTZ-60:ITIC possess highly efficient photo-induced exciton dissociation and charge transport processes, which agrees with the higher EQE and $J_{\mathrm{sc}}$ values of the related PSCs.

The hole/electron mobilities $\left(\mu_{\mathrm{h}} / \mu_{\mathrm{e}}\right)$ are measured using the space charge limited current method (Fig. S4). The $\mu_{\mathrm{h}} / \mu_{\mathrm{e}}$ were $2.84 / 0.65 \times 10^{-4}, 4.48 / 1.82 \times 10^{-4}, 6.27 / 3.65 \times 10^{-4}, 3.92 / 1.45 \times$ $10^{-4}$, and $3.59 / 1.11 \times 10^{-4} \mathrm{~cm}^{2} \cdot \mathrm{V}^{-1} \cdot \mathrm{s}^{-1}$ for the devices based on polymer donors PSBZ, PSBTZ-80, PSBTZ-60, PSBTZ-40, and PSTZ, respectively. The relatively high $\mu_{\mathrm{h}} / \mu_{\mathrm{e}}$ values and low $\mu_{\mathrm{h}} / \mu_{\mathrm{e}}$ ratio imply more effective and balanced charge transport in the PSBTZ-60:ITIC-based device, and thus a high PCE can be achieved for the PSCs.

The surface and bulk morphologies of polymer:ITIC blend films were also studied. For atomic force microscopy (AFM) images $(5 \mu \mathrm{m} \times 5 \mu \mathrm{m})$ (Fig. 6a-e), all the blend films show clear polymer aggregation. Moreover, the PSBTZ-60:ITIC blend film showed a smoother surface with a smaller root-mean-square roughness $\left(R_{\mathrm{q}}\right)$ of $1.17 \mathrm{~nm}$ compared to the blend films of PSBZ:ITIC (2.23 nm), PSBTZ-80:ITIC (1.80 $\mathrm{nm})$, PSBTZ-40:ITIC (1.77 nm), and PSTZ:ITIC $(1.73 \mathrm{~nm})$. For transmission electron microscopy (TEM) images (Fig. $6 \mathrm{f}-\mathrm{j}$ ), all the blend films display the regular fibril texture, although only the PSBTZ-60:ITIC blend film has a relatively suitable phase separation. The small surface roughness and suitable phase separation with a fibril texture are beneficial to exciton separation and charge transport and hence improved the

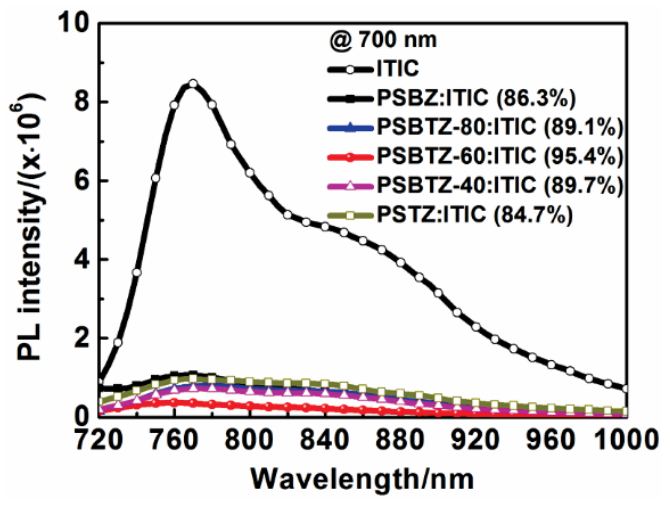

Fig. 5 The PL spectra of ITIC and the corresponding blend films at an excitation wavelength of $700 \mathrm{~nm}$. 


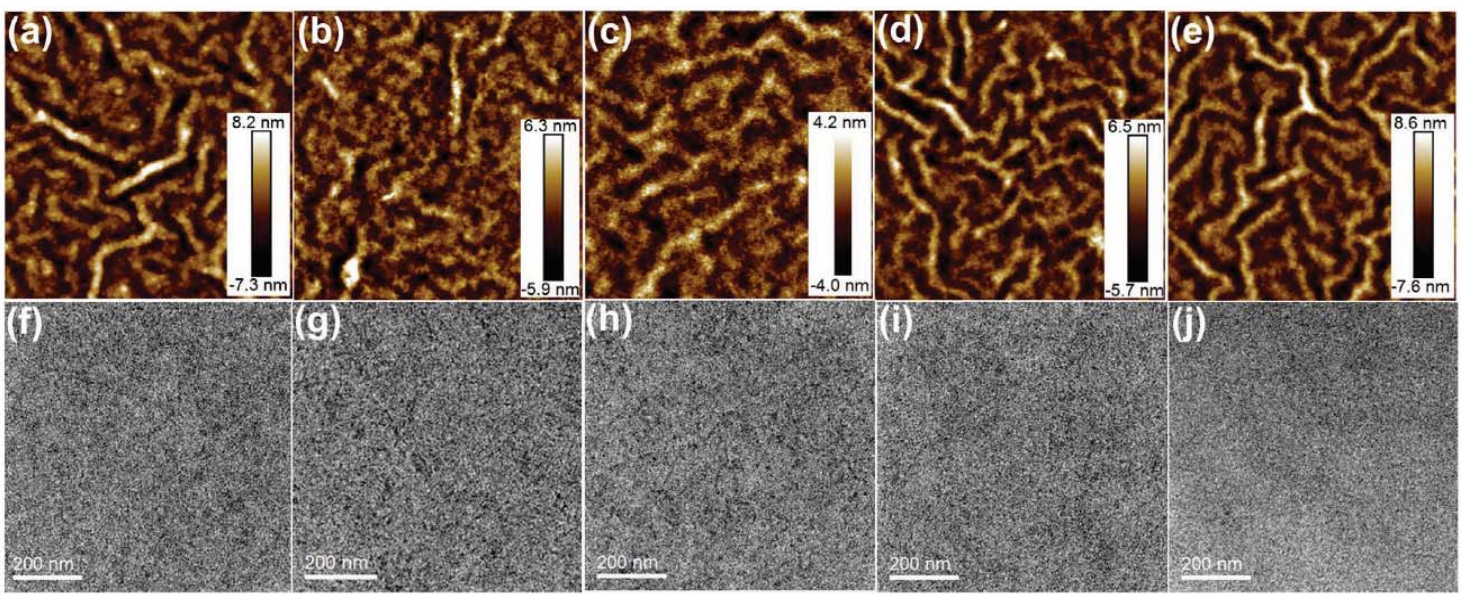

Fig. 6 (a-e) AFM and (f-j) TEM images.

(a and f) PSBZ:ITIC, (b and g) PSBTZ-80:ITIC, (c and h) PSBTZ-60:ITIC, (d and i) PSBTZ-40:ITIC and (e and j) PSTZ:ITIC blend films.

photovoltaic performance of PSCs.

\section{Conclusions}

A series of WBG random terpolymers based on BDTT-S as donor unit, FBTz and TTz as acceptor units were designed and synthesized for photovoltaic applications. By adjusting the molar ratio of two acceptor units in polymerization, the absorbance and energy levels of terpolymers can be effectively modulated. The terpolymer namely PSBTZ-60 showed the highest absorption coefficient and moderated energy levels. As a result, the PSCs based on PSBTZ-60:ITIC processed by the halogen-free solvents achieved a high PCE of $10.3 \%$ with a high $V_{\text {oc }}$ of $0.91 \mathrm{~V}$, improved $J_{\text {sc }}$ of $18.0 \mathrm{~mA} \cdot \mathrm{cm}^{-2}$ and $\mathrm{FF}$ of $62.7 \%$, which is obviously superior to the PSCs based on binary polymer donors PSBZ (8.1\%) and PSTZ (8.5\%). These results indicate that the random terpolymerization is a simple and practical strategy to design and optimize high-performance polymer photovoltaic materials.

Acknowledgment: This work is dedicated to Prof. Yongfang Li on the occasion of his 70th birthday.

Supporting Information: available free of charge via the internet at http://www.whxb.pku.edu.cn.

\section{References}

(1) Hou, J.; Inganäs, O.; Friend, R. H.; Gao, F. Nat. Mater. 2018, 17, 119. doi: $10.1038 /$ nmat5063

(2) Lin, Y.; Zhan, X. Adv. Energy Mater. 2015, 5, 1501063. doi: 10.1002/aenm.201501063

(3) Zhang, Z. G.; Yang, Y.; Yao, J.; Xue, L.; Chen, S.; Li, X.; Morrison, W.; Yang, C.; Li, Y. Angew. Chem. Int. Ed. 2017, 56, 13503. doi: 10.1002/anie.201707678

(4) Fan, B.; Ying, L.; Zhu, P.; Pan, F.; Liu, F.; Chen, J.; Huang, F.; Cao, Y. Adv. Mater. 2017, 29, 1703906. doi: 10.1002/adma.201703906
(5) Xu, Z.; Fan, Q.; Meng, X.; Guo, X.; Su, W.; Ma, W.; Zhang, M.; Li, Y. Chem. Mater. 2017, 29, 4811. doi: 10.1021/acs.chemmater.7b00729

(6) Li, S.; Liu, W.; Shi, M.; Mai, J.; Lau, T. K.; Wan, J.; Lu, X.; Li, C. Z.; Chen, H. Energy Environ. Sci. 2016, 9, 604. doi: 10.1039/c5ee03481g

(7) Fei, Z.; Eisner, F. D.; Jiao, X.; Azzouzi, M.; Röhr, J. A.; Han, Y.; Shahid, M.; Chesman, A. S. R.; Easton, C. D.; McNeill, C. R.; et al. Adv. Mater. 2018, 30, 1705209. doi: 10.1002/adma.201705209

(8) Zhao, W.; Li, S.; Yao, H.; Zhang, S.; Zhang, Y.; Yang, B.; Hou, J. J. Am. Chem. Soc. 2017, 139, 7148. doi: 10.1021/jacs.7b02677

(9) Fan, Q.; Su, W.; Wang, Y.; Guo, B.; Jiang, Y.; Guo, X.; Liu, F.; Thomas, P. R.; Zhang, M. J.; Li, Y. F. Sci. China Chem. 2018, doi: 10.1007/s11426-017-9199-1

(10) Lin, Y.; Wang, J.; Zhang, Z. G.; Bai, H.; Li, Y.; Zhu, D.; Zhan, X. Adv. Mater. 2015, 27, 1170. doi: 10.1002/adma.201404317

(11) Xu, X.; Yu, T.; Bi, Z.; Ma, W.; Li, Y.; Peng, Q. Adv. Mater. 2017, 30 , 1703973. doi: 10.1002/adma.201703973

(12) Lin, Y.; Zhang, Z.; Bai, H.; Wang, J.; Yao, Y.; Li, Y.; Zhu, D.; Zhan, X. Energy Environ. Sci. 2015, 8, 610. doi: 10.1039/c4ee03424d

(13) Dai, S.; Zhao, F.; Zhang, Q.; Lau, T. K.; Li, T.; Liu, K.; Ling, Q.; Wang, C.; Lu, X.; You, W.; et al. J. Am. Chem. Soc. 2017, 139, 1336. doi: $10.1021 /$ jacs.6b12755

(14) Liu, Y.; Zhang, Z.; Feng, S.; Li, M.; Wu, L.; Hou, R.; Xu, X.; Chen, X.; Bo, Z. J. Am. Chem. Soc. 2017, 139, 3356. doi: $10.1021 /$ jacs. 7 b00566

(15) Shi, X.; Chen, J.; Gao, K.; Zuo, L.; Yao, Z.; Liu, F.; Tang, J.; Jen, A. K. Y. Adv. Energy Mater. 2018, doi: 10.1002/aenm.201702831

(16) Kan, B.; Zhang, J.; Liu, F.; Wan, X.; Li, C.; Ke, X.; Wang, Y.; Feng, H.; Zhang, Y.; Long, G.; et al. Adv. Mater. 2017, 30, 1704904. doi: 10.1002/adma.201704904

(17) Luo, Z.; Bin, H.; Liu, T.; Zhang, Z.; Yang, Y.; Zhong, C.; Qiu, B.; Li, G.; Gao, W.; Xie, D.; et al. Adv. Mater. 2018, 
doi: 10.1002/adma.201706124

(18) Li, Y.; Lin, J. D.; Che, X.; Qu, Y.; Liu, F.; Liao, L. S.; Forrest, S. R. J. Am. Chem. Soc. 2017, 139, 17114. doi: 10.1021/jacs.7b11278

(19) Zhou, Z.; Liu, W.; Zhang, Z.; Liu, F.; Yan, H.; Zhu, X. Adv. Mater. 2017, 29, 1704510. doi: 10.1002/adma. 201704510

(20) Yang, Y.; Zhang, Z.; Bin, H.; Chen, S.; Gao, L.; Xue, L.; Yang, C.; Li, Y. J. Am. Chem. Soc. 2016, 138, 15011. doi: 10.1021/jacs.6b09110

(21) Zhao, W.; Qian, D.; Zhang, S.; Li, S.; Inganäs, O.; Gao, F.; Hou, J. Adv. Mater. 2016, 28, 4734. doi: 10.1002/adma.201600281

(22) Bin, H.; Zhang, Z. G.; Gao, L.; Chen, S.; Zhong, L.; Xue, L.; Yang, C.; Li, Y. J. Am. Chem. Soc. 2016, 138, 4657. doi: $10.1021 /$ jacs.6b01744

(23) Xue, L.; Yang, Y.; Xu, J.; Zhang, C.; Bin, H.; Zhang, Z. G.; Qiu, B.; Li, X.; Sun, C.; Gao, L.; et al. Adv. Mater. 2017, 29, 1703344. doi: 10.1002/adma.201703344

(24) Bin, H.; Gao, L.; Zhang, Z. G.; Yang, Y.; Zhang, Y.; Zhang, C.; Chen, S.; Xue, L.; Yang, C.; Xiao, M.; Li, Y. Nat. Commun. 2016, 7, 13651. doi: $10.1038 /$ ncomms 13651

(25) Fan, Q.; Su, W.; Guo, X.; Wang, Y.; Chen, J.; Ye, C.; Zhang, M.; Li, Y. J. Mater. Chem. A 2017, 5, 9204. doi: 10.1039/c7ta02075a

(26) Fan, Q.; Su, W.; Meng, X.; Guo, X.; Li, G.; Ma, W.; Zhang, M.; Li, Y. Sol. RRL 2017, 1, 1700020. doi: 10.1002/solr.201700020

(27) Fan, Q.; Wang, Y.; Zhang, M.; Wu, B.; Guo, X.; Jiang, Y.; Li, W.; Guo, B.; Ye, C.; Su, W.; et al. Adv. Mater. 2018, 30, 1704546. doi: 10.1002/adma.201704546

(28) Wang, Y.; Fan, Q.; Guo, X.; Li, W.; Guo, B.; Su, W.; Ou, X.; Zhang, M, J. Mater. Chem. A 2017, 5, 22180. doi: 10.1039/c7ta07785h

(29) Su, W.; Fan, Q.; Guo, X.; Meng, X.; Bi, Z.; Ma, W.; Zhang, M.; Li, Y. Nano Energy 2017, 38, 510. doi: 10.1016/j.nanoen.2017.05.060

(30) Guo, B.; Li, W.; Guo, X.; Meng, X.; Ma, W.; Zhang, M.; Li, Y. Adv. Mater. 2017, 29, 1702291. doi: 10.1002/adma.201702291

(31) Chen, S.; Liu, Y.; Zhang, L.; Chow, P. C. Y.; Wang, Z.; Zhang, G.; Ma, W.; Yan, H. J. Am. Chem. Soc. 2017, 139, 6298. doi: 10.1021/jacs.7b01606

(32) Liu, D.; Wang, J.; Gu, C.; Li, Y.; Bao, X.; Yang, R. Adv. Mater. 2018, 30, 1705870. doi: 10.1002/adma.201705870

(33) Kang, T. E.; Kim, K. H.; Kim, B. J. J. Mater. Chem. A 2014, 2, 15252. doi: $10.1039 / \mathrm{c} 4 \mathrm{ta} 02426 \mathrm{e}$

(34) Duan, C.; Gao, K.; Franeker, J. J.; Liu, F.; Wienk, M. M.; Janssen, R. A. J. J. Am. Chem. Soc. 2016, 138, 10782. doi: 10.1021/jacs.6b06418

(35) Fan, Q.; Liu, Y.; Xiao, M.; Su, W.; Gao, H.; Chen, J.; Tan, H.; Wang, Y.; Yang, R.; Zhu, W. J. Mater. Chem. C 2015, 3, 6240. doi: $10.1039 / \mathrm{c} 5 \mathrm{tc} 00785 \mathrm{~b}$

(36) Fan, Q.; Xu, X.; Liu, Y.; Su, W.; He, X.; Zhang, Y.; Tan, H.; Wang, Y.; Peng, Q.; Zhu, W. Polym. Chem. 2016, 7, 1747. doi: $10.1039 / \mathrm{c} 5$ py01985k

(37) Chen, S.; Cho, H. J.; Lee, J.; Yang, Y.; Zhang, Z. G.; Li, Y.; Yang, C. Adv. Energy Mater. 2017, 7, 1701125. doi: 10.1002/aenm.201701125

(38) Zhang, M.; Guo, X.; Zhang, S.; Hou, J. Adv. Mater. 2014, 26, 1118. doi: 10.1002/adma.201304427

(39) Fan, Q.; Su, W.; Guo, X.; Guo, B.; Li, W.; Zhang, Y.; Wang, K.; Zhang, M.; Li, Y. Adv. Energy Mater. 2016, 6, 1600430. doi: 10.1002/aenm.201600430

(40) Zhang, M.; Guo, X.; Ma, W.; Ade, H.; Hou, J. Adv. Mater. 2015, 27, 4655. doi: 10.1002/adma.201502110

(41) Blom, P. W.; Mihailetchi, V. D.; Koster, L. J.; Markov. D. E. Adv. Mater. 2007, 19, 1551. doi: 10.1002/adma.200601093

(42) Fan, Q.; Xu, Z.; Guo, X.; Meng, X.; Li, W.; Su, W.; Ou, X.; Ma, W.; Zhang, M.; Li, Y. Nano Energy 2017, 40, 20. doi: 10.1016/j.nanoen.2017.07.047

(43) Fan, Q.; Su, W.; Guo, X.; Zhang, X.; Xu, Z.; Guo, B.; Jiang, L.; Zhang M.; Li Y. J. Mater. Chem. A 2017, 5, 5106. doi: 10.1039/c6ta11240d

(44) Fan, Q.; Zhu, Q.; Xu, Z.; Su, W.; Chen, J.; Wu, J.; Guo, X.; Ma, W.; Zhang, M.; Li, Y. Nano Energy 2018, 48, 413. doi: 10.1016/j.nanoen.2018.04.002 